\title{
Reduction of Hemolysis Without Reoperation Following Mitral Valve Repair
}

\author{
Masaru Inoue, MD; Bunji Kaku, MD*; Hounin Kanaya, MD*; \\ Takio Ohka, MD*; Mikio Ueda, MD**; Seki Masahiro, MD***; \\ Masami Shimizu, MD; Hiroshi Mabuchi, MD
}

\begin{abstract}
Hemolytic anemia following mitral valve repair and annular ring placement is uncommon compared with mitral valve replacement. A 60-year-old man, who had undergone mitral valve repair with a Duran ring, developed hemolytic anemia and needed a blood transfusion. Transesophageal echocardiography revealed a paravalvular mitral regurgitation jet colliding with the Duran ring. Most cases of severe hemolysis after mitral valve repair have undergone reoperation, but in the present case study, the hemolysis after mitral valve repair reduced without the need for reoperation, although the paravalvular mitral regurgitation jet continued to collide with the Duran ring. (Circ J 2003; 67: 799-801)
\end{abstract}

Key Words: Hemolysis; Mitral valve repair; Reoperation

$\mathbf{H}$ emolytic anemia is uncommon after mitral valve repair and only a few cases have been reported. Although it is thought that rapid acceleration, fragmentation and collision of mitral regurgitation jets may be associated with high shear stress and cause hemolysis, 1,2 the precise mechanisms are not understood. In addition, the course of severe hemolysis after mitral valve repair has not been established, although in most cases the hemolysis improves with reoperation? ${ }^{-11}$ We report a patient who developed a severe hemolytic anemia after mitral valve repair that was reduced without the need for reoperation.

\section{Case Report}

A 60-year-old man suffered from shortness of breath because of severe mitral regurgitation secondary to the prolapse of the posterior mitral leaflet. Transthoracic echocardiography revealed severe mitral regurgitation filling the whole left atrium from the medial scallop of the posterior mitral leaflet. The dimension of the left atrium in systole phase and the left ventricle in diastole was $53 \mathrm{~mm}$ and $58 \mathrm{~mm}$, respectively. Surgery was performed under cardiopulmonary bypass, in mild hypothermia. Myocardial protection was afforded with cold crystalloid cardioplegia. A left paraseptal atriotomy was performed. The prolapsing medial scallop of the posterior mitral leaflet was resected, and the edge of leaflet was sewn onto a mitral annulus. A Duran flexible ring was sutured and fixed along the mitral

(Received December 26, 2001; revised manuscript received April 2, 2002; accepted April 12, 2002)

Molecular Genetics of Cardiovascular Disorders, Division of Cardiovascular Medicine, Graduate School of Medical Science, Kanazawa University, and Divisions of $*$ Cardiology, $* *$ Hematology and $* * *$ Cardiovascular Surgery, Ishikawa Prefectural Hospital, Kanazawa, Japan

Mailing address: Masaru Inoue, MD, Molecular Genetics of Cardiovascular Disorders, Division of Cardiovascular Medicine, Graduate School of Medical Science, Kanazawa University, 13-1 Takara-machi, Kanazawa 920-8640, Japan. E-mail: masaru@im2.m.kanazawa-u.ac. jp annulus. A water injection test confirmed no regurgitation. Transthoracic echocardiography 10 days after the mitral valve repair showed mild mitral regurgitation, reaching the deep left atrium from the posterior mitral commissure. The dimension of the left atrium in systole and the left ventricle in diastole was $34 \mathrm{~mm}$ and $45 \mathrm{~mm}$, respectively. Three weeks after the mitral valve repair, the patient was discharged with no complaints. After 2 months, he was readmitted complaining of fatigue and shortness of breath. His palpebral conjunctivae were anemic and bulbar conjunctivae icteric, but splenomegaly was not apparent. Laboratory data were as follows: red blood cell (RBC): $206 \times 10^{4} \mu \mathrm{l}$; hemoglobin: $6.2 \mathrm{~g} / \mathrm{dl}$; haptoglobin: $<10 \mathrm{mg} / \mathrm{dl}$; reticulocytes: $15.6 \times 10^{4} \mu \mathrm{l}$; lactate dehydrogenase $(\mathrm{LDH})$ : 3,235 IU/L; total bilirubin: $1.6 \mathrm{mg} / \mathrm{dl}$. All these values had been within the normal range 5 months earlier. The Donath-Landsteiner test, Coombs test, Ham test and sugar water test were all negative. Drug-induced hemolytic anemia was not apparent, because there was no reduction of hemolysis after stopping the administration of any drug without furosemide, which was administered before the mitral valve repair. The

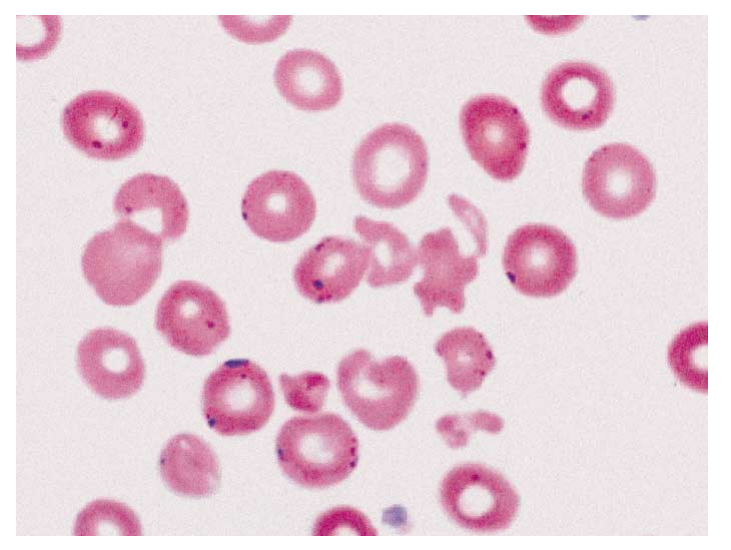

Fig 1. Peripheral blood smear showing many fragmented red blood cells. 

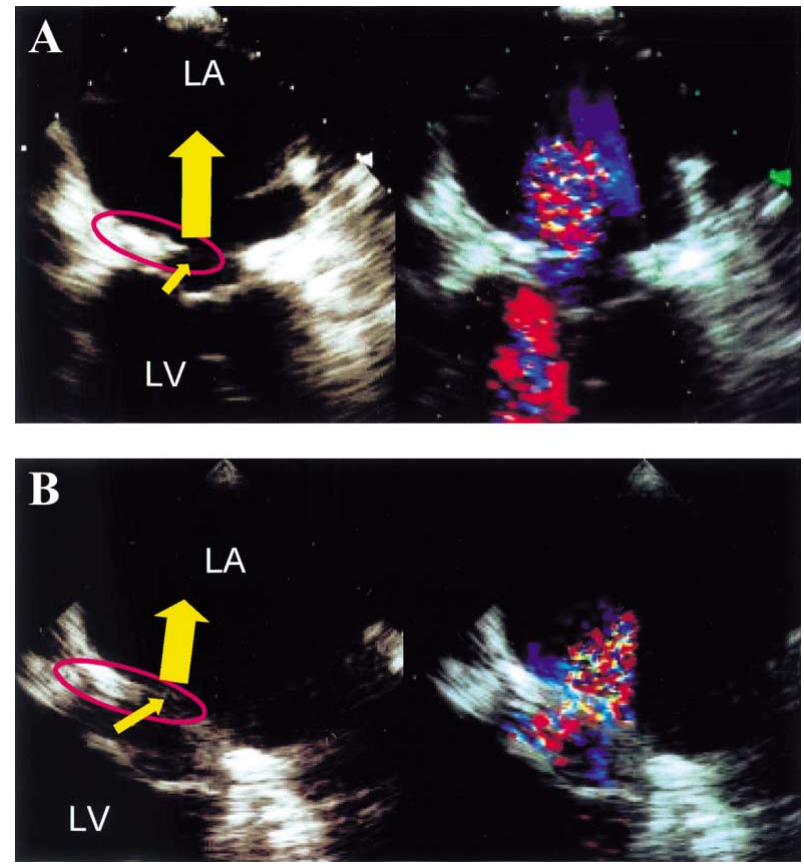

Fig 2. Transesophageal echocardiographs (A) at initial examination and (B) after reduction of hemolysis. The arrows show the direction of the mitral regurgitation, which was changed by collision with the Duran ring, shown in the circle both before and after the reduction of hemolysis. LA, left atrium; LV, left ventricle.

patient did not have any significant history, other than gastric cancer for which he had undergone a partial resection of the stomach; however, no source of bleeding could be found by gastroscopy or colonoscopy at that time. A peripheral blood smear showed many fragmented RBCs (Fig 1). Transthoracic echocardiography showed a moderate mitral regurgitation that did not fill the whole left atrium, but extended deeply from the posterior mitral commissure. The dimension of left atrium in the systolic phase and left ventricle in the diastolic phase was $26 \mathrm{~mm}$ and $48 \mathrm{~mm}$, respectively. The velocity of the mitral regurgitation jet was $3.3 \mathrm{~m} / \mathrm{s}$. Transesophageal echocardiography showed a moderate mitral regurgitation jet from the posterior mitral commissure colliding with the Duran ring (Fig 2A). Dehiscence of the Duran ring was not apparent. The patient received $400 \mathrm{ml}$ of packed RBCs and his symptoms improved over several months. We recommended that he undergo reoperation, but he rejected our recommendation and carried on receiving blood transfusions in the outpatient clinic without any adverse effect, such as renal dysfunction. The total amount of packed RBCs received was $2,400 \mathrm{ml}$. Unexpectedly, the hemolysis was reduced gradually without blood transfusion over 5 months and his RBC count was $344 \times 10^{4} \mu \mathrm{l}$, hemoglobin $7.3 \mathrm{~g} / \mathrm{dl}$, reticulocytes $7.1 \times 10^{4} \mu 1$, LDH $459 \mathrm{IU} / \mathrm{L}$ and total bilirubin $0.8 \mathrm{mg} / \mathrm{dl}$ at 1.5 years after the mitral valve repair. However, some fragmented RBCs remained apparent in the peripheral blood smear. Transesophageal echocardiography still showed a moderate regurgitation jet with a velocity of $3.6 \mathrm{~m} / \mathrm{s}$, colliding with the Duran ring, as recorded previously (Fig 2B). He has not needed any subsequent blood transfusion.

\section{Discussion}

Increased intravascular hemolysis occurs in the majority of patients with mechanical prosthetic valvular replacement and the incidence of hemolytic anemia varies from $5 \%$ to $15 \%$ ! $^{2}$ In contrast, RBC trauma and hemolysis following mitral valve repair and annular ring placement is uncommon because there are no moving mechanical parts or prosthetic leaflets. Only 7 patients among 1,548 who had underwent mitral valve repair needed reoperation for hemolytic anemia. The mechanisms of hemolysis following mitral valve repair have been reported to include dehisced annuloplasty rings producing para-ring regurgitant jets $3,8,11$ protruding perivalvular suture material that provided a site of impact for circulating RBCs, $7,9,13$ 'whiplash motion' of residual, free-floating chordae tendineae within a hyperkinetic left ventricular chamber ${ }^{10}$ nonendothelialization of foreign materials such as sutures or rings ${ }^{6}$ and a small but turbulent regurgitation jet against the left atrial walls Rapid acceleration, fragmentation and collision jets are associated with high shear stress, and may cause mitral prosthetic hemolysis, whereas free and slow deceleration jets are not? The mechanism of hemolysis observed after mitral valve repair most commonly involves direct collision of the regurgitation jet with an annuloplasty ring and appears to be independent of the severity of mitral regurgitation? In the present case, a high velocity, paravalvular mitral regurgitation jet collided with the Duran ring and may have caused the hemolysis.

Hemolytic anemia caused by prosthetic valves can be managed effectively with oral iron therapy in almost all patients, and reoperation, primarily for refractory hemolytic anemia, is seldom necessary and has not been consistently successful! ${ }^{2}$ On the other hand, an improvement in the hemolytic anemia following reoperation has been reported in many cases. ${ }^{2-11}$ Because of the severe hemolysis requiring a blood transfusion, we recommended that our patient undergo reoperation, but unexpectedly, the hemolysis reduced without reoperation, although a moderate mitral regurgitation jet remained. Slowed velocity caused by propranolol may reduce the shearing stress between RBCs and foreign material, ${ }^{14}$ but in this case, the hemolysis was reduced without an apparent change in velocity or blood pressure. Endothelialization of the Duran ring may have reduced the damage to the RBCs; prosthetic materials usually become endothelialized rapidly, within several weeks, but recurrent or residual mitral regurgitation jets may prevent the endothelialization and cause hemolysis at this site. In addition, it has been reported that incomplete endothelialization of the prosthetic material employed in the initial mitral repair was present in 11 of 12 patients reoperated for hemolysis, that the interval between initial repair and reoperation was 2.9 months, and that the site of incomplete endothelialization was not visible on transesophageal echocardiographic examination in any of these patients? Although it is difficult to know without inspection whether endothelialization really has occurred in the present patient, the important outcome is that hemolysis was reduced over the span of several months and that reoperation was not necessary.

It is important that the appropriate time for reoperation is not lost during refractory hemolytic anemia, but we had a rare case whose severe hemolysis after mitral valve repair was reduced without reoperation, over the span of several months. 


\section{References}

1. Garcia MJ, Vandervoort P, Stewart WJ, Lytle BW, Cosgrove DM III, Thomas JD, et al. Mechanisms of hemolysis with mitral prosthetic regurgitation: Study using transesophageal echocardiography and fluid dynamic simulation. J Am Coll Cardiol 1996; 27: 399-406.

2. Yeo TC, Freeman WK, Schaff HV, Orszulak TA. Mechanisms of hemolysis after mitral valve repair: Assessment by serial echocardiography. J Am Coll Cardiol 1998; 32: 717-723.

3. Ward RP, Sugeng L, Weinert L, Korcarz C, Verdino RJ, Spencer KT, et al. Hemolysis after mitral valve repair. Circulation 2000; 101: 695-696.

4. Cerfolio RJ, Orszulak TA, Pluth JR, Harmsen WS, Schaff HV. Reoperation after valve repair for mitral regurgitation: Early and intermediate results. J Thorac Cardiovasc Surg 1996; 111: 1177 1184.

5. Stoschitzky K, Starz I, Anelli-Monti M, Rigler B, Bauer F, Klein W. Transfusion-requiring haemolytic anaemia after mitral-valve repair. Lancet 1996; 347: 765.

6. Mestres CA, Soo CS, Sim EKW, Adebo OA, Yan P, Lee CN. Intravascular hemolysis after mitral valve repair: A word of caution. Eur J Cardio-thorac Surg 1992; 6: 103-105.

7. Dilip KA, Vachaspathy P, Clarke B, Walker DM, Thomas RD,
Monro JL. Haemolysis following mitral valve repair. J Cardiovasc Surg 1992; 33: 568-569.

8. Mok P, Lieberman EH, Lilly LS, Schafer AI, DiSesa VJ, Rutherford CR. Severe hemolytic anemia following mitral valve repair. Am Heart J 1989; 117: 1171-1173.

9. Warnes C, Honey M, Brooks N, Davies J, Gorman A, Parker N. Mechanical haemolytic anaemia after valve repair operations for non-rheumatic mitral regurgitation. Br Heart J 1980; 44: 381 -385.

10. Gupta SC, Suryaprasad AG. Mechanical hemolytic anemia after repair of ruptured chordae tendineae of mitral valve apparatus. Angiology 1979; 30: 776-779.

11. Moisey CU, Manohitharajah SM, Tovey LAD, Deverall PB. Hemolytic anemia in a child in association with congenital mitral valve disease. J Thorac Cardiovasc Surg 1972; 63: 765-768.

12. Kloster FE. Complications of artificial heart valves. JAMA 1979; 241: $2201-2203$.

13. Goldberger AL, Orth R, Moores WY. Severe hemolytic anemia after attempted. repair of paraprosthetic mitral regurgitation. Am Heart $J$ 1982; 104: 1381-1382.

14. Okita Y, Miki S, Kusuhara K, Ueda Y, Tahata T, Yamanaka K. Propranolol for intractable hemolysis after open heart operation. Ann Thorac Surg 1991; 52: 1158-1160. 